\title{
A randomised controlled trial of time-limited individual placement and support: IPS-LITE trial
}

Tom Burns, Ksenija Yeeles, Oliver Langford, Maria Vazquez Montes, Jennifer Burgess and Catriona Anderson

\section{Background}

Individual placement and support (IPS) has been repeatedly demonstrated to be the most effective form of mental health vocational rehabilitation. Its no-discharge policy plus fixed caseloads, however, makes it expensive to provide.

\section{Aims}

To test whether introducing a time limit for IPS would significantly alter its clinical effectiveness and consequently its potential cost-effectiveness.

\section{Method}

Referrals to an IPS service were randomly allocated to either standard IPS or to time-limited IPS (IPS-LITE). IPS-LITE participants were referred back to their mental health teams if still unemployed at 9 months or after 4 months employment support. The primary outcome at 18 months was working for 1 day. Secondary outcomes comprised other vocational measures plus clinical and social functioning. The differential rates of discharge were used to calculate a notional increased capacity and to model potential rates and costs of employment.

\section{Results}

A total of 123 patients were randomised and data were collected on 120 patients at 18 months. The two groups (IPS-LITE = 62 and IPS =61) were well matched at baseline.
Rates of employment were equal at 18 months (IPS-LITE $=24$ $(41 \%)$ and IPS $=27(46 \%))$ at which time $57(97 \%)$ had been discharged from the IPS-LITE service and 16 (28\%) from IPS Only 11 patients (4 IPS-LITE and 7 IPS) obtained their first employment after 9 months. There were no significant differences in any other outcomes. IPS-LITE discharges generated a potential capacity increase of $46.5 \%$ compared to $12.7 \%$ in IPS which would translate into 35.8 returns to work in IPS-LITE compared to 30.6 in IPS over an 18-month period if the rates remained constant.

\section{Conclusions}

IPS-LITE is equally effective to IPS and only minimal extra employment is gained by persisting beyond 9 months. If released capacity is utilised with similar outcomes, IPS-LITE results in an increase by $17 \%$ in numbers gaining employment within 18 months compared to IPS and will increase with prolonged follow-up. IPS-LITE may be more cost-effective and should be actively considered as an alternative within public services.

\section{Declaration of interest}

None.

\section{Copyright and usage}

(c) The Royal College of Psychiatrists 2015.
Mental disorders are set to become the major causes of disability worldwide $^{1}$ and are the leading cause of invalidity benefit in the $\mathrm{UK}^{2}$ Individual placement and support (IPS) is a form of vocational rehabilitation based on eight principles (Box 1) including individualised job finding and rapid, direct placement without prolonged and structured preparatory rehabilitation. ${ }^{3,4}$ It has consistently demonstrated greater success than stepwise rehabilitation, roughly doubling open employment rates over an 18-month follow-up. ${ }^{5}$ Consequently, it is recommended as the evidencebased intervention in a number of countries ${ }^{6-8}$ and several US states and it is government policy in the UK. ${ }^{9}$ Despite these policy recommendations implementation is patchy. This is in part because IPS's fixed caseloads ( 25 clients per IPS worker) and no-discharge policy restrict access and increase service costs although Latimer and colleagues ${ }^{10}$ have reported a flexible interpretation of this policy in US services with considerable variation in turnover and discharge. In the EQOLISE ${ }^{11}$ study of IPS in Europe, first employment was noted to be predominantly achieved during the first 9 months of intervention with many fewer in the subsequent nine. A similar early clustering has been reported in the ENDEAVOUR trial (in press BJPsych). We therefore decided to test a shortened form of IPS in which jobseeking support was limited to 9 months and support to those who acquired employment to 4 months. Those failing to obtain employment were referred back to their mental health team with an open invitation for re-referral. A similar offer of re-referral was made to those employed. Our hypothesis was that time-limited IPS (IPS-LITE) would be marginally less effective than IPS but that the increased throughput would result in more patients overall obtaining employment with the same staff input. It would therefore become more cost-effective.

Key principles of IPS are:

(a) focus on competitive employment;

(b) no exclusion criteria;

(c) rapid job search;

(d) integration with mental health team;

(e) attention to client's job preferences;

(f) time-unlimited support;

(g) benefits counselling; and

(h) active job development.

\section{Method}

\section{Design and setting}

The trial was an individual-level unblinded randomised controlled trial of IPS-LITE versus standard IPS. The setting was a nonstatutory mental health service in Oxford (RESTORE) funded by local commissioners and which offers a range of programmes for individuals with mental health problems (www.restore. org.uk). RESTORE had been operating a limited IPS service for 2 years and received a contract for an expansion to four full-time IPS workers to accept referrals from Oxfordshire Community Mental Health Teams (CMHTs). Enrolment of accepted patients 
into the IPS-LITE trial and its evaluation was a condition of the contract. The four IPS workers received internal training and supervision, and each was allocated to regular liaison meetings with either one or two CMHTs from whom they received their referrals. The trial was approved by the National Research Ethics Service Isle of Wight, Portsmouth and South East Hampshire Research Ethics Committee Ref. no. 09/H0501/53. Trial registration: ISRCTN28876952.

\section{Participants}

Eligible patients were (a) in contact with their CMHT for a minimum of 6 months and expected to remain in outpatient follow-up, (b) aged 18-65 years, (c) unemployed for a minimum of 6 months and (d) seeking employment in the open market.

\section{Recruitment and randomisation}

The four IPS workers met regularly with their allocated CMHTs to raise awareness of the service and relied on CMHT staff to refer potential patients. Referred patients were assessed by the IPS worker for their motivation for obtaining employment before being offered the service. Those found not to be motivated for open employment were often redirected to alternative supports or referred back to the CMHT. If offered IPS they had the difference between IPS and IPS-LITE explained by the IPS worker and if they consented to the trial then their details were forwarded to an independent statistician who conducted the randomisation. A non-deterministic minimisation algorithm ${ }^{12}$ was used to produce treatment groups balanced for five factors: age $<38 \mathrm{yrs}$ $v . \geqslant 38$ yrs (EQOLISE median age), gender, diagnosis (psychosis versus non-psychosis), duration of illness $(<5$ yrs $v$. $\geqslant 5$ yrs $)$ and previous employment (previously employed versus never employed). The first 2 patients were allocated using simple randomisation to avoid predictability. Subsequently, the minimisation algorithm was applied with an allocation ratio that is not fully deterministic: there was an $80 \%$ bias in favour of allocations that minimise the imbalance. If the marginal totals for the groups were the same at a given point, simple randomisation was then used.

IPS workers started their treatment without waiting for either randomisation or the baseline research interview, as there was no difference in initial practice. Blinding was not possible for the patient, the IPS worker or the independent researcher.

\section{Outcome measures}

\section{Primary outcome measure}

Employment in the open market for at least 1 day during the 18 months follow-up period. This is the internationally used measure in IPS outcome studies.

\section{Secondary outcome measures}

Vocational outcomes. Employment in the open market for at least 13 weeks. This is the outcome used for employment statistics by the UK National Audit Office. ${ }^{9}$
(a) Time to first employment.
(b) Number of days worked.
(c) Duration of longest employment (job tenure).

Clinical and social outcomes

(a) Psychiatric hospitalisation (Yes/No).

(b) The Hospital Anxiety and Depression Scale is a self- reported scale which assesses adverse anxiety and depression states by 14 items, each with range from 0 (no symptom) to 21 (severe symptoms). ${ }^{13}$ (c) The Brief Psychiatric Rating Scale is a researcher-rated scale of symptom severity on 24 domains (ranging from 24 (not present) to 168 (severe symptoms)). ${ }^{14}$

(d) The Manchester Short Assessment of Quality of Life (MANSA) assesses self-reported quality of life on 16 items with total score for 12 'subjective' items ratings ranging from 12 (could not be worse) to 84 (could not be better). ${ }^{15}$

(e) Euro-QoL is a self-reported, standardised measure of healthrelated quality of life on five dimensions. ${ }^{16}$

(f) Camberwell Assessment of Needs, Short Appraisal Schedule, research version assesses clinical and social needs with 22 items (ranging from 0 (no problem) to 22 (serious problem/ unmet needs)). ${ }^{17}$

(g) Social Outcomes Index summarises objective indicators of social outcomes in one overall score (range 0-6). ${ }^{18}$

(h) Global Assessment of Functioning (GAF) is a researcher-rated, single-item scale of impairment in functioning with range from 1 (severe impairment) to 100 (superior functioning). ${ }^{19}$

\section{Process evaluation}

All contacts with the IPS service were obtained from the IPS service record by researchers to confirm both the number and timing of contacts. Discharge dates from the service were obtained from RESTORE records. In a minority of patients without a recorded discharge but over 3 months without any contact directly preceding the final outcome assessment, the date of discharge was taken as the last contact. Dates of employment were obtained from the patient at the structured research interviews at 9 and 18 months. For patients not interviewed, primary and secondary outcome data were collected by phone or letter.

\section{Statistical analysis}

Before modelling, the data were checked for differences between allocation groups for all baseline characteristics using the appropriate test (chi-square test, $t$-test or Wilcoxon Rank Test), demonstrating no statistical significant differences between groups. The primary outcome was analysed using a logistic regression model to produce the effect size as an adjusted odds ratio with $95 \%$ CI. Secondary binary vocational outcomes were also analysed using a logistic regression model. Count outcomes (number of days worked, job tenure and number of contacts with service) were analysed using an adjusted negative binomial model that accommodated for the overdispersion and the results presented are rate ratios with $95 \%$ CIs. Treatment effects were estimated using hierarchical models with a random patient intercept. The effect sizes were adjusted for stratification factors.

The two survival curves (time to first job and time to discharge) were calculated using non-parametric Kaplan-Meier method. The corresponding adjusted hazard ratios (HRs) and 95\% CIs were estimated using a Cox Proportional Hazards model. For clinical and social outcome measures, we estimated treatment effect and change over time using hierarchical models with random patient intercept. For all effect sizes presented, the models were adjusted for stratification factors. All analyses were conducted according to the intention-to-treat principle and the results were obtained by using $\mathrm{R}$ software version 3.0.2.

\section{Results}

Figure 1, the CONSORT diagram, outlines the patient flow. Of 148 consented patients, 123 were randomised, 62 to IPS-LITE and 61 to IPS. The main reason for exclusion (18 individuals) 


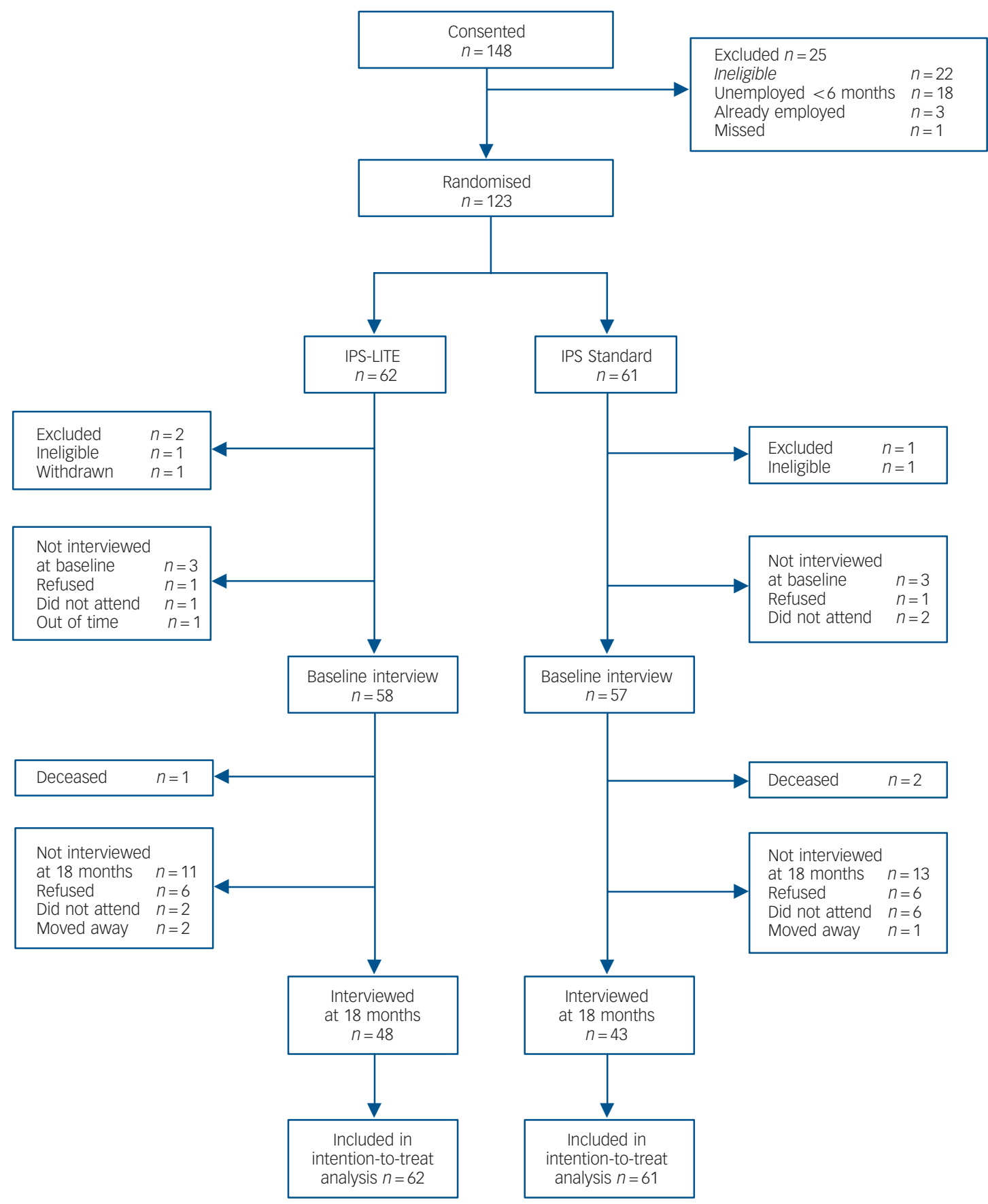

\section{Figure 1 Trial profile}

was duration of unemployment of less than 6 months. Of these 123 patients, 115 had a baseline interview with a researcher (IPS-LITE $=58$ and IPS $=57$ ) and 91 at 18 -month follow-up $($ IPS-LITE $=48$ and IPS $=43$ ).

Table 1 presents the baseline data for the participants showing there are no significant differences in baseline characteristics between the two groups. This was an early middle-aged group (mean 38 years), slightly more male subjects (59\%), 85\% white and $83 \%$ born in the UK. They had been ill for an average of 10 years and $58 \%$ were diagnosed with a psychotic disorder. Virtually, all (97\%) had worked at some time in the past and they had been currently unemployed for a median of 24 months.

Table 2 presents the employment outcomes. Overall, 51 patients $(43 \%)$ obtained employment and of these $33(28 \%)$ worked for at least 13 weeks. The median time to first job was 137 days (just over 4 months) and for those who did obtain employment the median duration of employment was 65 days (44 days in IPS-LITE and 74 days in IPS).The median duration for the longest employment was 122 days. In all of these vocational outcomes, the IPS group scored marginally better but in none was the difference statistically significant. Figure 2 shows the time to first job in the two groups. There is no difference in time to employment $(\mathrm{HR}=0.90, \mathrm{CI}=0.51-1.58, \quad P=0.71)$. Only 11 participants obtained employment after 9 months (4 in IPS-LITE and 7 in IPS).

Table 3 shows that there were no significant differences in the clinical or social outcomes. A total of 22 patients were admitted to hospital (10 to IPS-LITE and 12 to IPS) during the 18-month 


\begin{tabular}{|c|c|c|c|c|c|c|c|c|}
\hline & \multicolumn{2}{|c|}{ Total sample $(n=123)$} & \multicolumn{2}{|c|}{ Missing data } & \multicolumn{2}{|c|}{ IPS-LITE $(N=62)$} & \multicolumn{2}{|c|}{ IPS $(N=61)$} \\
\hline & $\begin{array}{l}\text { Mean } \\
\text { Median } \\
n\end{array}$ & $\begin{array}{c}\text { (s.d.) } \\
\text { [IQR] } \\
\%\end{array}$ & $n$ & $(\%)$ & $\begin{array}{c}\text { Mean } \\
\text { Median } \\
n\end{array}$ & $\begin{array}{c}\text { (s.d.) } \\
\text { [IQR] } \\
\%\end{array}$ & $\begin{array}{c}\text { Mean } \\
\text { Median } \\
n\end{array}$ & $\begin{array}{c}\text { (s.d.) } \\
{[\text { IQR] }} \\
\%\end{array}$ \\
\hline \multicolumn{9}{|l|}{ Demographics } \\
\hline Age, years & 38 & {$[30.0,47.0]$} & 0 & $(0 \%)$ & 39 & {$[29.3,48.0]$} & 38 & {$[32.0,46.0]$} \\
\hline Male & 72 & (59\%) & 0 & $(0 \%)$ & 35 & $(56 \%)$ & 37 & $(61 \%)$ \\
\hline General education, years & 13 & {$[11.0,14.0]$} & 5 & $(4 \%)$ & 13 & {$[12.0,14.0]$} & 13 & {$[11.0,13.0]$} \\
\hline Entered tertiary education & 49 & $(40 \%)$ & 5 & $(4 \%)$ & 29 & $(47 \%)$ & 20 & (33\%) \\
\hline \multicolumn{9}{|l|}{ Ethnicity } \\
\hline White & 102 & (85\%) & 3 & $(2 \%)$ & 55 & $(90 \%)$ & 47 & (80\%) \\
\hline Other & 18 & (15\%) & - & - & 6 & (10\%) & 12 & (20\%) \\
\hline Born in the UK & 99 & (83\%) & 4 & $(3 \%)$ & 51 & (84\%) & 48 & (83\%) \\
\hline \multicolumn{9}{|l|}{ Living situation } \\
\hline Married/co-habiting & 25 & (21\%) & 2 & $(2 \%)$ & 14 & (23\%) & 11 & $(18 \%)$ \\
\hline Independent accommodation & 104 & (89\%) & 6 & $(5 \%)$ & 55 & (95\%) & 49 & (83\%) \\
\hline Living alone & 50 & $(43 \%)$ & 7 & $(6 \%)$ & 24 & $(42 \%)$ & 26 & $(44 \%)$ \\
\hline \multicolumn{9}{|l|}{ Employment statistics } \\
\hline Worked previously & 119 & (97\%) & 0 & $(0 \%)$ & 60 & (97\%) & 59 & (97\%) \\
\hline Duration of current unemployment, months & 24 & {$[12.0,52.5]$} & 0 & $(0 \%)$ & 24 & {$[10.0,53.3]$} & 24 & {$[12.0,50.0]$} \\
\hline \multicolumn{9}{|l|}{ Diagnoses } \\
\hline Psychosis & 71 & (58\%) & 0 & $(0 \%)$ & 36 & (58\%) & 35 & (57\%) \\
\hline Non-psychosis & 52 & $(42 \%)$ & 0 & $(0 \%)$ & 26 & $(42 \%)$ & 26 & $(43 \%)$ \\
\hline \multicolumn{9}{|l|}{ Psychiatric history } \\
\hline Duration of illness, years & 10 & {$[3.5,17.0]$} & 0 & $(0 \%)$ & 12 & {$[4.3,18.5]$} & 8 & {$[3.0,16.0]$} \\
\hline Number of past psychiatric hospitalisations & 1 & {$[0.0,3.0]$} & 1 & $(1 \%)$ & 1 & {$[0.0,3.0]$} & 1 & {$[0.0,2.0]$} \\
\hline \multicolumn{9}{|l|}{ Clinical outcomes } \\
\hline $\begin{array}{l}\text { Brief Psychiatric Rating Scale, } \\
\text { range 24-168 }\end{array}$ & 38 & {$[34.0,45.0]$} & 8 & $(7 \%)$ & 37 & {$[34.0,43.0]$} & 40 & {$[34.0,46.0]$} \\
\hline $\begin{array}{l}\text { Global Assessment of Functioning (GAF), } \\
\text { range 1-100 }\end{array}$ & 60 & {$[52.0,65.0]$} & 8 & (7\%) & 60.5 & {$[52.0,67.3]$} & 59 & {$[52.0,63.0]$} \\
\hline Euro-QoL Index & 0.743 & {$[0.62,0.85]$} & 8 & (7\%) & 0.804 & {$[0.63,0.85]$} & 0.725 & {$[0.62,0.85]$} \\
\hline Euro-QoL Visual Analogue Scale & 54.5 & -19.8 & 9 & $(7 \%)$ & 52.3 & -18.8 & 56.8 & -20.6 \\
\hline
\end{tabular}

\begin{tabular}{|c|c|c|c|c|c|c|c|c|c|c|c|}
\hline & \multicolumn{3}{|c|}{ Total sample $(n=123)$} & \multicolumn{3}{|c|}{ IPS-LITE $(n=62)$} & \multicolumn{3}{|c|}{ IPS $(n=61)$} & \multicolumn{2}{|c|}{ Effect size (ES) } \\
\hline & $\begin{array}{c}\text { Median } \\
n\end{array}$ & $\begin{array}{l}{[\mathrm{IQR}]} \\
(\%)\end{array}$ & $\begin{array}{l}\text { Sample } \\
\text { size }\end{array}$ & $\begin{array}{c}\text { Median } \\
n\end{array}$ & $\begin{array}{l}{[\mathrm{IQR}]} \\
(\%)\end{array}$ & $\begin{array}{l}\text { Sample } \\
\text { size }\end{array}$ & $\begin{array}{c}\text { Median } \\
n\end{array}$ & $\begin{array}{l}{[\mathrm{IQR}]} \\
(\%)\end{array}$ & $\begin{array}{l}\text { Sample } \\
\text { size }\end{array}$ & HR/OR/RR & $(95 \%$ Cl) \\
\hline $\begin{array}{l}\text { Employment outcomes } \\
\text { Worked for at least } 1 \text { day } \\
\text { Worked for at least } 13 \text { weeks }\end{array}$ & $\begin{array}{l}51 \\
33\end{array}$ & $\begin{array}{l}(43 \%) \\
(28 \%) \\
\end{array}$ & $\begin{array}{l}118 \\
118 \\
\end{array}$ & $\begin{array}{l}24 \\
15 \\
\end{array}$ & $\begin{array}{l}(41 \%) \\
(25 \%)\end{array}$ & $\begin{array}{l}59 \\
59\end{array}$ & $\begin{array}{l}27 \\
18\end{array}$ & $\begin{array}{l}(46 \%) \\
(31 \%)\end{array}$ & $\begin{array}{l}59 \\
59\end{array}$ & $\begin{array}{l}\mathrm{OR}=0.82 \\
\mathrm{OR}=0.75\end{array}$ & $\begin{array}{l}(0.38,1.78) \\
(0.32,1.73)\end{array}$ \\
\hline $\begin{array}{l}\text { For those who worked at least } 1 \text { dal } \\
\text { Number of days to first job } \\
\text { Number of days worked } \\
\text { Duration of longest employment, } \\
\text { days (includes part-time work) }\end{array}$ & $\begin{array}{c}137.0 \\
65.0 \\
122\end{array}$ & $\begin{array}{l}{[59.0,253.5]} \\
{[16.0,112.5]} \\
\\
{[49.0,232.0]}\end{array}$ & $\begin{array}{l}51 \\
51\end{array}$ & $\begin{array}{l}137.0 \\
44.0\end{array}$ & $\begin{array}{l}{[53.8,233.5]} \\
{[17.3,108.3]} \\
{[49.8,202.5]}\end{array}$ & $\begin{array}{l}24 \\
24\end{array}$ & $\begin{array}{l}136.5 \\
74.0\end{array}$ & $\begin{array}{l}{[68.8,282.5]} \\
{[16.0,123.0]} \\
{[66.5,264.0]}\end{array}$ & $\begin{array}{l}27 \\
27\end{array}$ & $\begin{array}{l}\mathrm{HR}=0.90 \\
\mathrm{RR}=0.94 \\
\mathrm{RR}=0.92\end{array}$ & $\begin{array}{l}(0.51,1.58) \\
(0.51,1.76) \\
(0.51,1.65)\end{array}$ \\
\hline
\end{tabular}

follow-up. Overall symptoms were marginally down and social outcome measures including quality of life, needs etc. were either unchanged or marginally better apart from the GAF which reduced from a mean of 57.9 to 54.3. None of these changes are clinically significant. There are no significant differences in these outcomes between the two arms other than a minor reduction in the 9-month MANSA score.

\section{Discharge and impact on capacity}

Figure 3 shows that IPS-LITE patients were rapidly discharged after 9 months. By 18 months, only two of the original patients were still on the IPS-LITE caseload as compared to 42 in IPS.
We calculated the potential capacity by summing the days from discharge/disengagement to the 18-month follow-up and dividing by 547 (days in 18 months). This generates the equivalent number of extra places available to take on new patients averaged out over 18 months. In the IPS-LITE group, this amounted to 15766 days (equivalent to 28.8 extra patients) and in the IPS group it amounted to 4263 days (equivalent to 7.8 extra patients). We then assumed that these new patients would have the same rate of employment as the measured samples (41\% in IPS-LITE and $46 \%$ in IPS). This is equivalent to 11.81 new jobs in IPS-LITE and 3.64 new jobs in IPS.

If all four IPS workers were to regularly fill up their caseloads to the recommended 25 at all times then over a period of 18 
Table 3 Clinical outcomes at baseline, 9 month and 18 months

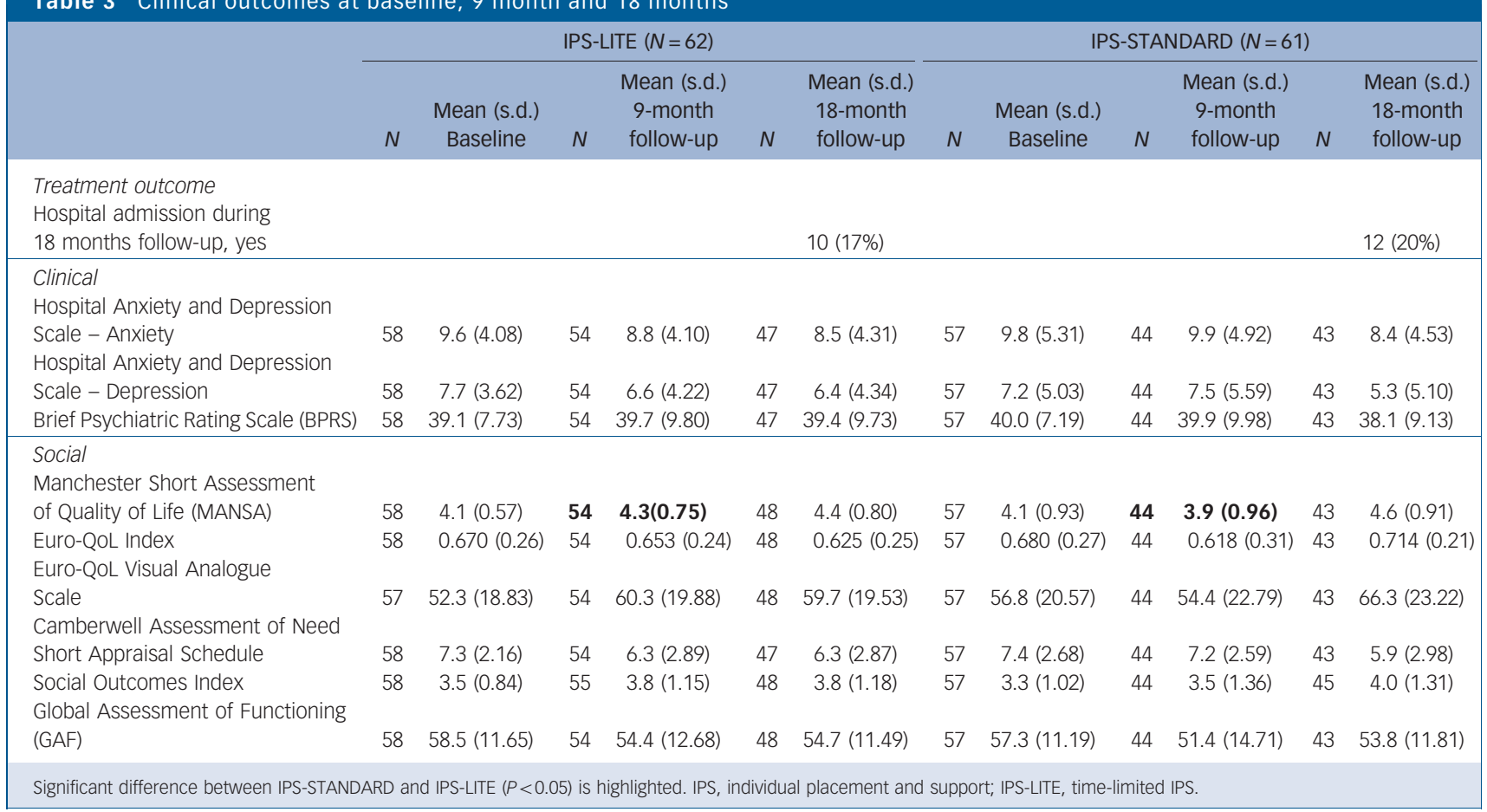

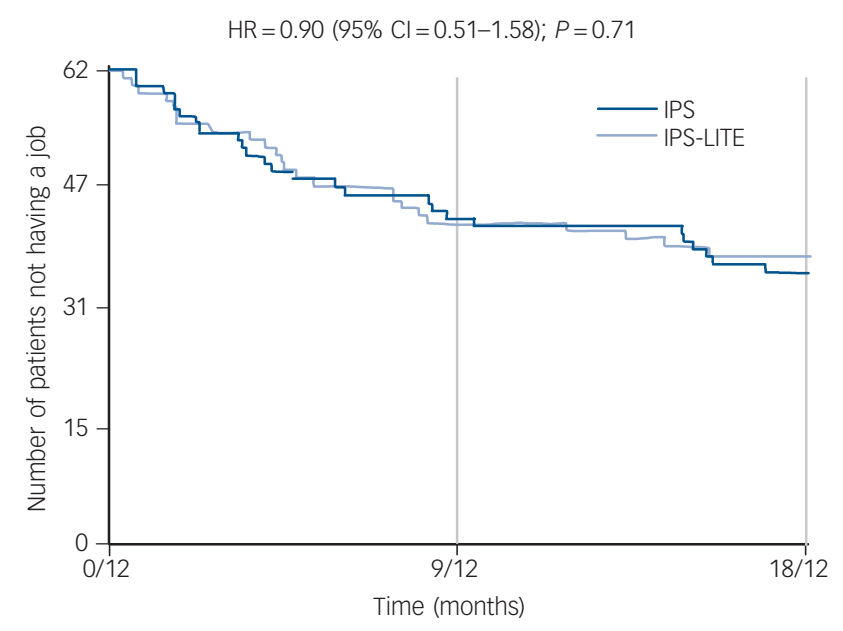

Fig. 2 Time to first job.

HR, hazard ratio; IPS, individual placement and support; IPS-LITE, time-limited IPS

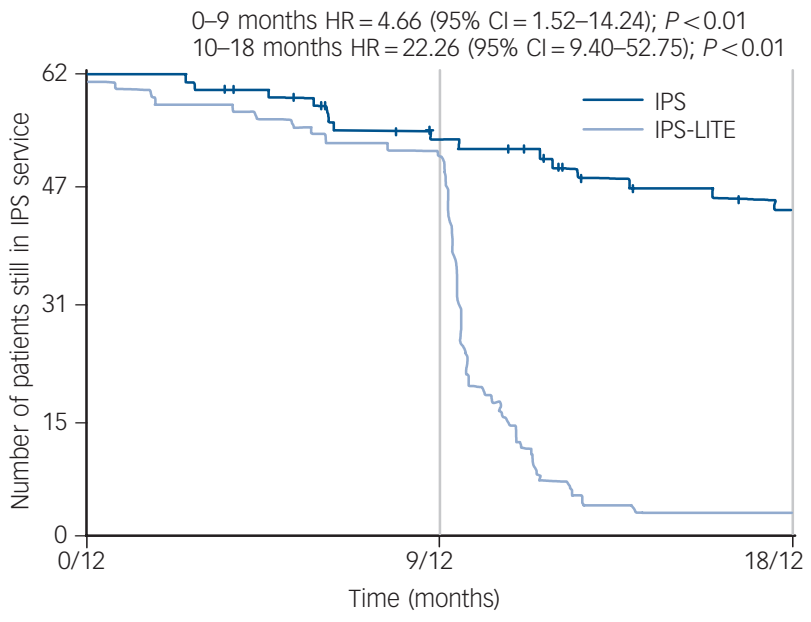

Fig. 3 Time to discharge from IPS service.

HR, hazard ratio; IPS, individual placement and support; IPS-LITE, time-limited IPS. months two IPS-LITE workers would provide input to 91 patients and two IPS workers would provide input to 69 patients. Based on the figures derived from this trial (IPS-LITE $=41 \%$, IPS $=46 \%$ ), the two IPS-LITE workers would get 35.81 patients back into employment and the two IPS workers would achieve 30.64, equivalent to a $17 \%$ increase in efficiency.

\section{Discussion}

IPS principles include a 'no-discharge' policy. Active support is not withdrawn although patients may disengage from services. This no-discharge policy has been found to be difficult to operate in some services ${ }^{20}$ and powerfully restricts access to IPS in resource-limited public services. Our trial indicates that little is lost in terms of obtaining employment by limiting the duration of involvement of IPS services to 9 months. Of the 51 patients who did obtain employment during the trial, $40(78 \%)$ did so within their first 9 months. Six of the 11 patients who obtained employment after 9 months were no longer in receipt of IPS care - all four of the IPS-LITE patients and two of the seven IPS patients who had disengaged from the service. This leaves only five patients $(10 \%)$ who can confidently be assumed to have obtained employment as a direct consequence of continuing IPS involvement.

While it is a condition of such services that patients are genuinely motivated for work this may not always remain consistent. Some patients may profess themselves keen for employment and find the reality more daunting than they anticipated. Others may lose their commitment for a range of reasons including changes in their mental state or in family and social circumstances. This cannot be accurately predicted and all patients who entered the IPS-LITE trial, as in other IPS trials, had been assessed to be strongly motivated for employment. Our findings would suggest that there 
is merit in deciding on a time limit to avoid persisting with patients who are currently unlikely to succeed. Further trials could test whether subsequent re-referral of such discharged patients is successful or not. This would help to disentangle whether the original failure was due to temporary aspects of the clinical condition or reflected more enduring motivational and attitudinal characteristics.

An unanticipated finding in our trial was the six patients who obtained employment without current active input. There are no good data to estimate the likelihood that this is the same as or greater than would have been expected without IPS input. The numbers are small and the clinical characteristics do not permit confidently comparing with other non-input control groups. However, it is worth considering that there may be some enduring effect of the IPS input.

Our findings confirm the utility of the internationally accepted IPS primary outcome measure of one day of open employment. Of the 51 patients who achieved this 33 also achieved the UK employment target of remaining in their job for 13 weeks.

\section{IS IPS-LITE cost-effective?}

We have resisted speculative forward-modelling of costs for the two services and restricted ourselves to presenting the data for the 18 months of the study. Our calculated potential 91 patients for two IPS-LITE workers versus 69 patients for two IPS workers is highly conservative. It does not take into account the number of IPS patients who would remain on the caseload yet unemployed beyond the 18 months of the study.

The rate of throughput will diverge markedly in subsequent years as new cohorts of IPS-LITE patients are recruited while the IPS caseload only dwindles slowly. If an IPS-LITE alternative is to be pursued then a more sophisticated cost-effectiveness study with more comprehensive data collection would be indicated. However, the figures we obtain with a potential $17 \%$ increase in number of jobs with the same resource would suggest that IPS-LITE may be more cost-effective than routine IPS. A larger and longer trial would be needed to test this definitively.

\section{Conclusions}

Our study confirms the growing international literature that IPS as a highly successful form of vocational rehabilitation for individuals with enduring mental health disorders. It also confirms that this can be successfully delivered within non-statutory services that provide adequate staff training and support. A limit of the duration of support to 9 months appears not to significantly reduce the number obtaining employment. Whether limiting in-work support reduces the average duration of employment remains an open question, and our study is not powered to answer this and gives mixed, non-significant results. Staff were easily able to adapt to the adjusted model of care and the improved access with no significant fall-off in effectiveness would suggest that there may be potential improvements in cost-effectiveness that would increase over time. Given current difficulties in implementing IPS in times of austerity, we would recommend that a timelimited model should be the first choice for new services. Different durations should be tested to identify the optimal service configuration.
Tom Burns, Professor of Social Psychiatry, Ksenija Yeeles, Research Fellow, Department of Psychiatry, University of Oxford, Oliver Langford, NIHR Research Methods Fellow, Nuffield Department of Primary Care Health Sciences, University of Oxford, Maria Vazquez Montes, Senior Statistician \& NIHR Oxford BRC Research Fellow, Nuffield Department of Primary Care Health Sciences \& the Centre for Statistics in Medicine, University of Oxford, Department of Primary Care Health Sciences, University of Oxford, Jennifer Burgess, Research Assistant, Catriona Anderson, Research Assistant, Department of Psychiatry, University of Oxford.

Correspondence: Professor Tom Burns, Department of Psychiatry, University of oxford, Warneford Hospital, Oxford OX2 6NW. Email: tom.burns@psych.ox.ac.uk

First received 29 May 2014, final revision 13 Aug 2014, accepted 17 Nov 2014

\section{References}

1 Mathers C, Lopez AD. Updated Projections of Global Mortality and Burden of Disease, 2002-2030: Data Sources, Methods and Results. WHO, 2005.

2 Henderson M, Glozier N, Holland EK. Long term sickness absence. BMJ 2005; 330: 802-3.

3 Bond GR, Kukla M. Impact of follow-along support on job tenure in the individual placement and support model. J Nerv Mental Dis 2011; 199: 150-5. 10.1097/NMD.0b013e31820c752f.

4 Bond GR, Kukla M. Is job tenure brief in individual placement and support (IPS) employment programs? Psychiatr Serv 2011; 62: 950-3.

5 Bond GR, Drake RE, Becker DR. An update on randomized controlled trials of evidence-based supported employment. Psychiatr Rehabil J 2008; 31: 280-90.

6 Latimer EA, Lecomte T, Becker DR, Drake RE, Duclos I, Piat M, et al. Generalisability of the individual placement and support model of supported employment: results of a Canadian randomised controlled trial. Br J Psychiatry 2006; 189: 65-73.

7 Wong K, Chiu R, Tang B, Mak D, Liu J, Chiu SN. A randomized controlled trial of a supported employment program for persons with long-term mental illness in Hong Kong. Psychiatr Serv 2008; 59: 84-90.

8 Hoffmann $\mathrm{H}$, Jäckel D, Glauser S, Kupper Z. A randomised controlled trial of the efficacy of supported employment. Acta Psychiatr Scand 2012; 125: 157-67.

9 The Comptroller and Auditor General. Sustainable Employment: Supporting People to Stay in Work and Advance. National Audit Office, 2007.

10 Latimer EA, Bush PW, Becker DR, Drake RE, Bond GR. The cost of high-fidelity supported employment programs for people with severe mental illness. Psychiatr Serv 2004; 55: 401-6.

11 Burns T, Catty J, Becker T, Drake RE, Fioritti A, Knapp M, et al. The effectiveness of supported employment for people with severe mental illness: a randomised controlled trial. Lancet 2007; 370: 1146-52.

12 Pocock SJ. Clinical Trials: A Practical Approach. Wiley, 1983.

13 Zigmond AS, Snaith RP. The hospital anxiety and depression scale. Acta Psychiatr Scand 1983; 67: 361-70.

14 Lukoff D, Nuechterlein K, Ventura J. Manual for expanded Brief Psychiatric Rating Scale (BPRS). Schizophr Bull 1986; 12: 594-602.

15 Priebe S, Huxley $\mathrm{P}$, Knight S, Evans S. Application and results of the Manchester Short Assessment of Quality of Life (MANSA). Int J Soc Psychiatry 1999; 45: 7-12

16 Brooks R. EuroQol: the current state of play. Health Policy 1996; 37: 53-72.

17 Phelan M, Slade M, Thornicroft G, Dunn G, Holloway F, Wykes T, et al. The Camberwell Assessment of Need: the validity and reliability of an instrument to assess the needs of people with severe mental illness. Br J Psychiatry 1995; 167: 589-95.

18 Priebe S, Watzke S, Hansson L, Burns T. Objective social outcomes index (SIX): a method to summarise objective indicators of social outcomes in mental health care. Acta Psychiatr Scand 2008; 118(1): 57-63.

19 Goldman H, Skodol AE, Lave TR. Revising axis V for DSM-IV: a review of measures of social functioning. Am J Psychiatry 1992; 149: 1148-56.

20 Howard LM, Heslin $M$, Leese $M$, Mccrone $P$, Rice $C$, Jarrett $M$, et al. Supported employment: randomised controlled trial. Br J Psychiatry 2010; 196: 404-11. 